\title{
On the rationality of Decision Aiding processes
}

\author{
Y. Meinard ${ }^{\mathrm{a}, *}$, A. Tsoukiàs ${ }^{\mathrm{a}}$ \\ ${ }^{a}$ Université Paris-Dauphine, PSL Research University, CNRS, UMR [7243], LAMSADE, \\ 75016 PARIS, FRANCE
}

\begin{abstract}
The notion of rationality plays a crucial role in Decision Aiding (DA), both as a scientific discipline and as a professional practice. Indeed, a pervasive and possibly constitutive feature of DA is that it constantly faces challenges as to whether it is valid, legitimate, useful, practical, etc. Rationality plays a pivotal role in participating to determine whether DA fulfills such requirements. In this article, we take advantage of arguments developed in the philosophical literature, mainly by Habermas, to introduce a framework defining a series of conceptions of rationality. We use this framework in order to introduce a typology of DA approaches, distinguishing objectivist, conformist, adjustive and reflexive approaches. Whereas the underlying conception of rationality plays a key role in determining the features of DA processes, we argue that tools are largely independent of conceptions of rationality. Our reasoning has direct operational implications, which makes it of distinctive interest, not only for philosophers and operational research theoreticians, but also for practitioners. We explain how practitioners should reason in practice to identify which DA approach they should implement in a given situation. We then explain how they can take advantage of our analysis to entrench the legitimacy and validity of their recommendations.
\end{abstract}

Keywords: Decision processes, Problem structuring, Philosophy of operational research, Legitimacy, Validity.

\footnotetext{
${ }^{*}$ Corresponding author
} 


\section{Introduction}

Any practicing decision analyst knows that, in any decision aiding that $\mathrm{s} / \mathrm{he}$ provides, at some point the issue of the validity or legitimacy of her/his work will resurface. Other requirements, such as usefulness or practicality, are similarly often emphasized. Such challenges are a pervasive and possibly constitutive feature of decision aiding (DA), both as an academic discipline and as a professional practice. Focussing on the first two requirements, Landry and collaborators [25, 26] famously argued that their precise content evolved as the discipline of operational research (OR) and its applications historically unfolded. More generally, one easily understands that, behind their commonsensical relevance, requirements such as legitimacy, validity, practicality and usefulness, are interrelated in complex ways. They implicitly refer to ideals of scientificity, computability and deontology, and take different meanings depending on contexts and available technologies.

Because DA practice is oriented towards solving concrete problems, these justification requirements should arguably be understood through the lenses of "pragmatism" $[34,35]$, in the philosophical sense given to this term in particular by Peirce in his famous "pragmatic maxim":

"Consider what effects, that might conceivably have practical bearings, we conceive the object of our conception (a sign, a word, a communication) to have. Then our conception of these effects is the whole of our conception of the object." [41]

In its application to the above requirements, this maxim or principle suggests that it is illusory and irrelevant to look for all-purposes, general definitions - let alone to pretend to deduce them from general abstract concepts. However, as Ulrich [58] argues, the pragmatic maxim does not deny the importance of conceptual reflection, be it only because applying it requires to bound the "effects" and "bearings" that should be taken into account.

In line with this idea, our aim in this article is to elaborate an account of what we take to be one of the most important factors underlying all the above requirements: rationality. We do not claim that rationality is 
all there is to validity or legitimacy or any other similar requirement, but rather that it is a determining factor for all of them - a determining factor to which it can prove particularly useful to appeal in practice to vindicate the credentials of our analyses and recommendations.

This idea is naturally suggested by the distinctive aim of DA to introduce "elements of rationality" in handling problems [55]. Similarly, the very concept of "rational choice" [1], which plays an important role in many DA frameworks, echoes the importance of rationality. References to rationality are hence pervasive in DA, but what exactly is its role in DA? To articulate clearly this question, it is useful to introduce the following definitions.

We consider situations schematized as interactions between an Analyst (A) and a Client (C) or a decision-maker (the distinction between the two, though important in some contexts, will be left aside here). This schematic representation is a profound simplification of real-life DA interactions, but it will prove sufficient here. Such interactions involve a series of entities:

A first set of entities, which we will term "tools", encompasses: mathematical procedures (sequences of elementary mathematical operations transforming a mathematical structure into another, e.g. inverting a matrix, transitively closing a graph, etc.); algorithms (sequences of mathematical procedures with a precise information handling purpose, e.g. the simplex algorithm, variants of the SAT-algorithm, etc.); protocols (sequences of mathematical procedures and/or input/output steps allowing to collect information and to interact with $\mathrm{C}$, e.g. the construction of a utility function, indifference swaps in conjoint measurement, etc.); methods (sets of algorithms and protocols allowing to analyse information for some DA purpose, e.g. the Branch and Bound method, multiple criteria decision analysis methods, etc.); models (structural representations of the elaborated information, see the definition "evaluation model" in [6] and [55]).

As opposed to tools, a "decision aiding process" refers to all the work that $\mathrm{A}$ does in his endeavour to use tools to proceed towards the resolution of the problems he tackles when aiding C [55].

Lastly, we define an "approach" as a way by which A conducts a DA process. 
These definitions allow articulating the following more specific questions concerning the role of rationality in DA:

- Q1: Should one consider that rationality characterizes tools or processes or approaches or all of them?

- Q2: What does a "rationality" requirement amount to when applied to the above entities?

- Q3: Are there various conceptions of rationality and, in that case, is it possible to establish a correspondence between specific types of DA tools, processes or approaches and specific conceptions of rationality?

In this article, we first develop a framework distinguishing a series of markedly different conceptions of rationality relevant for DA (Section 2). We then use these ideas to develop a typology of DA approaches (Section 3 ). We then compare our typology with classical ones from the literature (Section 4), before concluding (Section 5).

\section{Conceptions of rationality and rational decision aiding}

What does "rationality" mean? The whole history of western philosophy can be seen as a tale of competing answers to this question [18]. A comprehensive review falls beyond the scope of this article. Our point here is rather that different approaches to DA can be distinguished by the conception of rationality in which they are entrenched.

We start by mentioning a couple of keystone references in the conceptualisation of rationality. We then introduce a typology based on Habermas' philosophy [18]. Numerous authors have already elaborated on the relevance of various aspects of Habermas' writings (such as his theory of the ideal speech situation [57] or his analysis of the logic of social sciences [16]) for the philosophy of OR. Here we focus on a very specific aspect of his work - his reading of the history of philosophical and sociological "models of action" - and we show how his rationale on this issue can be extended to develop an understanding of the notion of rationality relevant from a DA point of view. 
2.1. The centrality and polysemy of references to "rationality" in the DA literature

References to rationality are pervasive in the DA and OR literature, in particular in methodological and epistemological contributions. Ormerod notices that " $[\mathrm{m}]$ ost operational research practitioners would claim that the advice they give to their clients is underpinned by rationality" ([36]), and he introduces his "foundationalist view" of OR by recalling the importance of tackling questions such as "do we conduct our investigations in a rational way, are our methods rational, and can the advice we give be rationally justified and defended?" ([39], p. 1). Similarly, Ulrich [57] justified the elaboration of his "critical heuristics" approach by the need to be able to produce rational justifications in OR.

However, this reference to "rationality" is not unequivocal. Ormerod indeed also highlights that several notions of rationality are typically at play when one investigates the rationality of a decision-making process, or when a DA process strives to render a decision rational ([37], p. 478). Similarly, Jackson [21] highlights how a paradigm such the one of "critical system thinking" can be crippled if a reductive understanding of the concept of rationality prevents it from encompassing several forms of rationality. A striking illustration of this polysemy of references to rationality is the contrast between Ulrich's approach, in which the rationality requirement is tightly associated with references to value-judgments and the ethics and responsibilities of experts, and the much more restrictive understanding of rationality epitomized by rational choice theory. Associated with this diversity of understandings of rationality, this notion is linked in the literature with several networks of concepts, some of them highlighting its links with concepts of logic (e.g. [39]), others with the notion of inquiry (e.g. [34]), still other with the notion of justification (e.g. [35]).

Our aim in this article is neither to provide an extensive review of these contributions, nor to criticize them. Our aim is to provide a clarification of the notion of rationality, as it can be used from the point of view of DA. This clarification should be seen as complementary, and in a sense preliminary, to the above literature, in the sense that we propose a basic investigation 
of a concept that the above literature takes as a building block, to tackle more elaborate questions, such as how to provide rational foundations to OR theory and practices [39], how to elaborate a framework to identify and discuss normative and practical implications of DA processes [57] or how to foster creativity in problem solving [15]?

\subsection{First steps towards conceptualizing rationality}

Standard dictionary definitions of "rationality" refer to ideas such as having good sense and sound judgement (hence phrasings such as "his rationality was impaired by anger"). The idea of acting based on reasoning and coherence are also typically mentioned: one establishes a principle and acts "rationally" if one remains coherent with it. "Coherence" here can refer to a reasoning principle, an objective to achieve, a procedure to follow, etc.

Beyond these commonsensical but barely informative ideas, the contemporary understanding of rationality in social sciences is largely associated with Weber [60]. This literature defines a form of rationality called "substantive" in terms of goal attainment: an agent is rational in that sense if $\mathrm{s} /$ he cogently chooses the means to achieve her/his objectives. By contrast, "procedural rationality" refers to adherence to a rule: when facing a problem, an agent is procedurally rational if s/he correctly uses the appropriate procedure.

Simon [50] famously pointed out that such models of rationality presuppose that agents have perfect knowledge of the objectives to attain, the rules to abide by and the resources needed. Such assumptions are demonstrably unrealistic in real-world decision processes. Simon $[49,51]$ accordingly observed that real decision-makers do not obey these rationality models. To overcome them, Simon introduced the concept of "bounded rationality". This approach is anchored in a principle of "satisficing" (a Scottish term that Simon revived to expose his views), according to which decision-makers typically content themselves with solutions that they subjectively and locally deem "satisficing". The bounded availability of information and resources, as well as bounded capacities to process information, result in a behaviour that is rational but falls short of the standards set by visions like Weber's. 


\subsection{Habermas' typology of models of action as template}

Both Weber's and Simon's understandings of rationality refer to the behaviour of a single agent who aims to be "rational", presumably to make sure or to convince her/himself that what s/he decides is the best possible option, or at least a satisfactory one (we purportedly use the term "satisfac-

tory" here, rather than Simon's "satisficing", because our argument aims to be more general). These visions of rationality ignore the social dimension of decision processes. They ignore that an agent's decision often involves other people, some of which have important stakes in the decision, and that the agent can be more concerned to convince them rather than her/himself.

Habermas' concept of "communicative action" [18] is powerful in addressing such concerns. To introduce it, Habermas claimed that the literature in sociology and philosophy has been mainly devoted to develop three "models of action", which are templates to represent and explain agent's actions and decisions:

- The strategic model accounts for an agent's actions and decisions in terms of objective facts, concerning the agent him/herself and the context.

- The norm-regulated model accounts for an agent's actions and decisions by striving to identify the justified or legitimate norms or expectations that the agent abides by.

- The dramaturgic model accounts for an agent's actions and decisions by striving to understand how the agent portrays her/himself and her/his inner consciousness before a public.

The first model does not deny that people take some expectations to be valid, have feelings and live experiences. It claims that these are epiphenomena useless to represent and explain decisions. Symmetrically, the second and third models take objective facts and, respectively, inner consciousness and valid expectations, as epiphenomena.

Habermas then noticed that these models share a key feature. All three are presented in the literature as third person accounts of observed behaviors. But all three can be used by actors themselves to respond to criticisms. 
If an agent is criticized on the grounds that $\mathrm{s} /$ he did not took the relevant facts into account, s/he can (implicitly or explicitly) take advantage of the strategic model and counter such criticisms by defending "validity claims" concerning the "objective truth" underlying her/his choices. Similarly, if $\mathrm{s} /$ he is criticized because $\mathrm{s} /$ he misidentified what $\mathrm{s} /$ he had to do or what $\mathrm{s} / \mathrm{he}$ was supposed to do, s/he can take advantage of the norm-regulated model and counter such criticisms by defending validity claims about her/his "normative rightness". Lastly, if $\mathrm{s} /$ he is criticized because her/his expressions were insincere, s/he can use the dramaturgic model and strive to entrench her/his "expressive or subjective truthfulness".

An agent can hence account for her/his own decisions thanks to these models. But, more importantly, s/he can also change her/his own behaviour in the light of: (i) the various accounts s/he can elaborate, (ii) criticisms $\mathrm{s} /$ he faces and (iii) the relevance of various accounts to counter criticisms.

To account for the dynamics of this process and the importance of interpersonal interactions, Habermas then introduced his notion of communicative action. This fourth model of action is a reflexive integration of the three other models: in this fourth model, the other models are conceived as frameworks that actors themselves can alternatively use in various situations to defend their actions and decisions. In different decision situations, agents raise validity claims with respect to one or several validity dimensions, and they face criticisms by defending their validity claims.

This pivotal step in Habermas' reasoning is introduced through his notion of "thematization", which captures the idea that agents typically behave in standardized or, one might say, "automatic" ways: they do not spend their time conceptualizing what they do, they most of the time simply do it. But they can, in some circumstances, step back from their usual way of behaving, take some aspects of their own behaviour as a theme for examination and questioning, and change their behavior as a result. Because thematization allows agents to improve their behavior by transforming "automatic" acts and decisions into acts and decisions that they are themselves better able to defend against criticisms, thematization is, in Habermas' reasoning, the basis of rationalization. This allows to articulate the following definition: 
Definition 1. "Rationality" refers to the quality of acts and decisions which is increased by agents when they thematize and modify aspects of their acts and decisions so as to improve their ability to counter criticisms.

\subsection{A four-terms typology of conceptions of rationality relevant to DA}

Here we want to use this understanding of rationality to elaborate a natural extension of Habermas' framework, that consists in defining four conceptions of rationality based on different kinds of thematizations. This idea allows us to introduce the following four-terms typology of conceptions of rationality:

- An agent acts according to the strategic conception of rationality if s/he thematizes, and therefore is ready to question and abandon, her/his belief in the existence of valid expectations that $\mathrm{s} /$ he should respect and in the importance of her/his inner life and feelings, but does not thematize the assumption that there are objective, external truths independent from her/his and others' thoughts and speech. In this conception, the essence of rationality is the quest of objective, independent truths.

- An agent acts according to the norm-regulated conception of rationality if $\mathrm{s} /$ he thematizes the assumption that there are objective, external truths and her/his belief in the importance of her/his inner life and feelings, but does not thematize the assumption that there are valid expectations that $\mathrm{s} /$ he ought to respect. In this conception, the essence of rationality is to act according to valid expectations.

- An agent acts according to the dramaturgic conception of rationality if $\mathrm{s} /$ he thematizes the assumptions that there are objective, external truths and that there exist valid expectations, but does not thematize the importance of her/his inner life and feelings. In this conception, the essence of rationality is to listen to one's inner life.

- An agent acts according to the communicative conception of rationality if s/he thematizes all three aspects: the importance of her/his inner life and feelings, the assumption that there are objective, external truths, and the assumption that there exist valid expectations. 
In this typology, rationality is no longer exclusively defined in terms of how an individual agent understands her/his own action and decisions or exclusively in terms of how an external observer can analyze them. An agent can be forced or incited or driven to thematize various elements of her/his actions and decisions because s/he is criticized by others, or because s/he wants to convince them of something. An agent can obviously decide on her/his own to thematize some aspects of her/his action, without communicating with anyone. But just like talking to oneself is only possible for someone who has learnt conversation in pluri-individual settings, similarly, solitary thematizations are derived from interpersonally-prompted ones.

\section{DA approaches as embodiments of conceptions of rationality}

In this section, we use our typology of conceptions of rationality to define four types of DA approaches, distinguished by the conception of rationality in which each is embedded.

In order to explain our typology in concrete terms, we also introduce two series of examples. For each item of the typology, we first spell out a fictive, explanatory example, and then an example of a real-life DA process. Because a choice had to be made between myriads of possible examples, and because we wanted the exposition to remain homogeneous, we arbitrarily chose a problem of locating stationing medical emergency vehicles to structure the explanatory examples, and environmental policies for real-life examples.

\subsection{The theory: four types of DA approaches}

\subsubsection{Objectivist DA approaches}

We call a DA approach "objectivist" when it is shaped by the strategic conception of rationality. Such an approach admits that there are such things as objective and unquestionable formulations of the problem facing $\mathrm{C}$, and objective and unquestionable solution(s) (or an objective and unquestionable absence of solution), independent of the idiosyncrasies of $\mathrm{C}$, her/his context of decision and the stakeholders concerned by her/his decisions.

In this approach, these objective formulations and solutions are not to be questioned during the DA process, they are a pre-requisite constraining the 
whole process. They can be defined by a philosophical theory, which is then taken to be true. For example, hedonistic utilitarianism is a doctrine stating that aggregate happiness, measured for example by experienced utility, should be maximized [53]. This doctrine can be used to define an objectivist DA approach, through which one assumes that the problem tackled (whatever it is) should be solved in such a way as to maximize aggregate happiness. More prosaically, the formulation of the problem can be dictated by the stated will of an authoritative third party, such as someone higher than $\mathrm{C}$ in the organization's hierarchy.

In an objectivist DA approach, the task of $\mathrm{C}$ and $\mathrm{A}$ is to compute the problem according to the adopted formulation and to identify the corresponding solutions (if any). Deviations from the standards set by these formulations and solutions reflect mistakes or shortcomings of C's, who should be aided in learning to decide in a "correct" way.

As opposed to the assumed objective truths defining what is here taken to be "correct", the two other aspects of action pinpointed by Habermas, valid expectations and inner consciousness, are admitted to be liable to be questioned by objectivist DA processes. For example, if $\mathrm{C}$ thinks that $\mathrm{s} /$ he is expected or has a duty to behave in a certain way, but this expectation is at odds with the recommandations produced, then the above expectations should be discarded. Similarly, if C's inner feelings or consciousness lead her/him to question the identified solution(s), C should hold them back.

Example (explanatory) 1. $C$ asks help from $A$ to find the minimum number of locations for stationing medical emergency vehicles so that every village in a region can be reached by an ambulance within a pre-specified number of minutes. This problem statement, including the objective to minimize and the maximum number of minutes, is taken as unquestionable by both $A$ and $C$. A develops an optimization model using a standard OR set covering model. The role of $C$, after formulating the request, is to provide the necessary data (average speed of the ambulances, eligible routes, etc.).

Example (real-life) 1. In the Ile-et-Vilaine department, in France, the local administration owns various areas considered to be of environmental value, and regularly asks, through public procurements, for decision help to consulting firms in order to elaborate management schemes for plant 
species and natural habitats. For these public procurements, the department uses contractual requirements elaborated by an authoritative third party, the Botanical Conservatory. The requirements specify the entities that the consulting firm will have to study, the methods that they will have to use, and how they should value and prioritize the various entities. All these elements are untouchable fixed points that both $A$ and $C$ are expected to take as absolute references. For more details see [29].

\subsubsection{Conformist DA approaches}

We call a DA approach "conformist" when it is shaped by the norm-regulated conception of rationality. These are approaches aimed at aiding $\mathrm{C}$ to make a decision that $\mathrm{s} /$ he and the other people involved will consider conform to what $\mathrm{C}$ is expected to do or has a duty to do, or conform to what appears satisfactory. The main threat that $\mathrm{C}$ is concerned to avoid is that her/his decision will create problems because other people consider that "that's not what has to be done". A's task is to identify relevant insights to understand the kinds of decisions and the features of decisions that render them "satisfactory" in the specific context of the DA process.

For the purpose of identifying such "satisfactory" decisions, this approach can draw on a vast literature empirically addressing human judgment and behaviour $[20,24,44]$. This literature often refers to "biases" because it was originally intended to overcome weaknesses of economic models settings unrealistic standards. But the reason why such studies provide the most important material for conformist approaches is independent of this academic dispute: it is that this literature produces descriptive accounts of the way people behave and expect others to behave. Beyond this literature, the material available for this approach may encompass organization theories, the past experience of C's organization, and other empirical knowledge about what works well or does not work well. Such accounts often involve rules of thumb, shared practices, "ways of doing things" which altogether delineate what an agent and the various other people involved will consider to be a satisfactory solution or decision.

In this approach, the core assumption is that there are justified expectations, things that "have to be done". As opposed to these assumed valid 
expectations, the two other aspects of action pinpointed by Habermas, theoretical truth and inner consciousness, are admitted to be liable to be questioned. If C's inner feelings or consciousness are at odds with the recommendations produced, then they must be discarded; similarly, if it appears that objective facts contradict the recommendations, it must be that these alleged facts are misconceptions or illusions.

Example (explanatory) 2. C asks help from $A$ to find where to locate stationing medical emergency vehicles in his area. A investigates how similar problems have been tackled in different regions, and gathers information about the settings that proved most acceptable to Clients and to the general population. Based on extensive questionnaire surveys and statistical analyses, s/he proposes a setting that s/he expect will not arouse any outcry.

Example (real-life) 2. Natura 2000 is a European-wide network of natural sites and agricultural lands benefiting from environmental regulation because they shelter species of wild fauna and flora or natural habitats considered of "community interest" according to European legislations. In France, this environmental regulation implies that, on each and every Natura 2000 site, a dedicated action plan must be carved out and implemented so as to ensure the conservation of the species and habitats concerned. However, as a matter of legal requirement, the action plan should be entirely "voluntary": it cannot involve any mandatory action and should be entirely based on the goodwill of stakeholders. To elaborate such voluntary action plans, local governments often ask decision help to consultants, whose job is then to implement consultation processes and studies of the economic and social processes at play in the area, so as to identify a series of actions that will appear acceptable and will be endorsed by stakeholders. A detailed account of such a process can be found for example in [32].

\subsubsection{Adjustive DA approaches}

We call a DA approach "adjustive" when it embodies the dramaturgic conception of rationality by tracking C's idiosyncrasies. An adjustive DA process is purportedly only suitable for a given $\mathrm{C}$ in a particular context, it aims to identify C's needs, preferences and values as well as possible, with minimum interference and maximal accuracy.

Since Raiffa's seminal RAND report [45] there has been a remarkable development in the DA literature in the direction of "client driven" decision 
modelling [5, 27, 59], suitable to unfold adjustive approaches. Although $\mathrm{C}$ can find it difficult to answer A's questions and/or can be unable to provide a complete description of the problem situation and her/his values, an adjustive approach will aim to provide an answer fitting C's information as well as possible. A's task is to learn about the problem and C's needs and preferences, and then prescribe the best solution given C's needs and preferences. If these needs and preferences appear to contradict alleged theoretical truths or to question supposedly justified norms, this means that the latter are ill-conceived.

Example (explanatory) 3. C asks help from $A$ to find where to locate stationing medical emergency vehicles in his territory. $C$ has preferences on the kind of setting $s /$ he wants to see implemented, s/he has priorities concerning the areas within her/his territory that s/he deems more important than others, and s/he has preferences concerning the balance to be reached between providing a service to her/his constituency and minimizing public expenditures. The task of $A$ is to take all these dimensions of $C$ 's preference into account to identify the setting that best matches her/his preferences.

Example (real-life) 3. In 2014, the local government in the French department of Gironde asked help from consultants through a public procurement procedure to evaluate and redefine its water environment policy. The department had conducted a water environment policy since 1999 without formalizing its proper objectives and ambitions. The various agents involved in the definition and implementation of this policy could only formulate a vague vision of their aims, and they wanted to clarify this vision by articulating a series of hierarchized ambitions. A's work was to help $C$ to understand and clarify its own aims and to formalize them. For more details see [31].

\subsubsection{Reflexive DA approaches}

We call a DA approach "reflexive" when it is based on the communicative conception of rationality. As opposed to the other three kinds of approaches, reflexive approaches do not start from any fixed, unquestionable reference point: both authoritative conceptions, behavioral expectations and inner preferences can be questioned. In line with, for instance, [2, 40, 52], reflexive approaches take the structuration of C's problem, its formulation, the identification of relevant tools, and the very genesis of preferences and be- 
havior, as integral parts of what the DA process has to construct, through continued interactions between $\mathrm{A}$ and $\mathrm{C}$.

Reflexive approaches distinctively emphasize two aspects of DA practice. First, they conceive DA as socio-technical interventions [10, 11], in which C and A both decisively influence the process and its outcome. This echoes the view, most prominently held by proponents of Problem Structuring Methods [46], that the social aspect of the intervention is as important as the technical aspect. Second, reflexive approaches understand DA processes as learning processes, where the $\mathrm{C}$ increases her/his knowledge about her/his situation and her/his preferences, which may change as a result (e.g. [13, 17]).

Example (explanatory) 4. $C$ asks help from $A$ to find where to locate stationing medical emergency vehicles in his territory. A starts by emphasizing that $C$ should pay attention to the very formulation of the problem s/he faces. Like in an adjustive approach, A leads $C$ to express her/his preferences over various aspects of the problem. But unlike in adjustive approaches, s/he does not assume that C's preferences are given and untouchable: s/he rather admits that the very process through which s/he leads $C$ to express her/his preferences can, and certainly should, lead her/him to form new preferences. Like in an adjustive approach, A pays great attention to how acceptable various solutions can prove to be. But here s/he uses the corresponding analysis to feed back her/his understanding of the problem. For example, based on her/his understanding of the importance that $C$ gives to her/his constituency's willingness to accept this or that solution, s/he can venture that C's problem might not really be one of stationing medical emergency vehicles, but one of ensuring a feeling of being taken care of by some parts of her/his constituency. Like in an objectivist approach, s/he assumes that some well-defined problems can be solved by specific existing tools, but $s /$ he is cautious not to distort the problem. In all this process, A works together with $C$, and the problem as they eventually manage to articulate and solve it can turn out to be very different from the one initially formulated by C.

Example (real-life) 4. In 2016, the local government in the French department of Charente-Maritime asked help from consultants through a public procurement procedure to elaborate its strategy for its so-called "Vulnerable Natural Areas" policy. The department had initially formulated its problem by referring to the elaboration of similar strategies in other French departments. However, A quickly understood that, even upstream the definition of 
a "Vulnerable Natural Areas" strategy, there were important questions that the department had neglected, concerning, in particular, the way it wanted to define the very point of this policy, the relationship that it should have with other environmental policies, the kind of influence that this policy could be granted when deciding how to allot the money devoted to various kinds of environmental policies, and so on. A therefore set out to redefine the precise scope of the mission with $C$, to identify with it a shared formulation of the key problems that they should tackle together. The elaboration of the strategy could thereby in the end be completed on firmer foundations. For the detailed story see [8].

\subsubsection{Intra-approaches differences}

Despite the important differences between approaches that we have just highlighted, within each of them, there can also be non-negligible differences. It is important to consider them in order to better understand the logic of the typology. Above, we already hinted at the main two variants that are encompassed within objectivist approaches: some are anchored in standards that are imposed by an authoritative third party, while others are anchored in standards derived from a (more or less implicit, more or less acknowledged) philosophical doctrine accepted or presupposed by $\mathrm{A}$ and $\mathrm{C}$ (or possibly imposed by one of them). Conformist approaches can be based on the idea that the best way to fulfill expectations is to imitate the others' behavior, while others can strive to identify the norms that happen to be accepted in the situation where the DA process takes place. Still others can claim that a normative, philosophical analysis of the norms that should be accepted is a more relevant source than an empirical analysis of the norms that factually happen to be accepted (a detailed explanation of this contrast falls beyond the scope of the present article; an example of such a reasoning is given in [19]). Prominent variants of the adjustive approach are distinguished by whether the process aims at fitting what one might call C's "shallow" preferences, that is, what he spontaneously expresses or reveals when the DA process is launched, or rather the more elaborate things that a dedicated part of the DA process allows her/him to express, such as her/his informed preferences (see for example [3]). Lastly, reflexive approaches can put more emphasis on various steps of the DA process: in particular, more 
emphasis can be put on either the formulation of the problem or in the construction of C's preferences.

\subsection{Operationalizing the theory}

Our analysis so far has distinguished four conceptions of rationality and four corresponding DA approaches. Although we have spelled out examples illustrating the four approaches in broad outlines, our reasoning unfolded at a theoretical and philosophical level. From the point of view of OR academics and DA practitionners, a natural question is whether our philosophical typology can be useful in practice.

The difficulty to operationalize philosophical theories has been emphasized by numerous authors, in particular Ormerod [38]. We argue that our reasoning does have direct operational implications, which makes it of distinctive interest, not only for philosophers and OR theoreticians, but also for practionners. To establish that point, we first explain how practitioners should reason in practice to identify which DA approach they should implement in a given situation. We then explain how they can take advantage of our analysis to entrench the legitimacy and validity of their recommendations.

\subsubsection{How to choose the DA approach to implement}

Recall that each of the four approaches presented in 3.1.1 to 3.1.4 is anchored in one of the conceptions of rationality defined in 2.3 , and each of these conceptions of rationality is defined on the basis of differential thematizations. This naturally suggest that, in a given decision situation, if a given thematization pattern is distinctively relevant, then the corresponding DA approach is appropriate.

One can easily identify concrete criteria to determine if the different thematization patterns associated with the strategic, norm-regulated and dramaturgic conceptions of rationality are relevant. Such criteria reflect the fact that, in a given situation, it is relevant to refrain from thematizing a given aspect of what determines how decisions are made. A prominent reason why this can be relevant is if the situation is such that the aspect at issue is an unalterable, binding constraint. In order to identify the relevant DA 
approach to implement, what we have to look at is therefore the constraints binding the DA process.

The DA approach for which this task is the easiest is the conformist one. Here we look for situations where it can be relevant to question anything except for the assumption that there are valid expectations that ought to be respected. As our real-life example in 3.1.2 already hinted at, this is typically the case in situations where most if not all the actors involved in the decision or potentially affected by it have clearly established and entrenched roles and statuses, so that C's chief aim is that her/his decision should fit smoothly in the existing governance pattern. These are situations where the dominant constraint is an irrevocable governance pattern.

The situations where an objectivist DA approach is relevant are those in which it appears relevant to assume that there are objective and unquestionable formulations of the problem facing $\mathrm{C}$, and objective and unquestionable solution(s). This is typically the case in situations in which the decision aiding process is tightly overseen by external experts or expertise institutions which are considered to be absolute references, and are therefore entrusted with imposing the methodologies and tools that A should use, monitoring and evaluating her/his work, and validating the recommendations s/he produces. These are situations where the dominant constraint is an unquestionable decision-aiding architecture.

The situations where an adjustive DA approach is in order are those where the dominant constraint rather comes from $\mathrm{C}$ her/himself, in the sense that what comes from her/him is granted prominent importance, whereas the other aspects liable to determine her/his decisions can be thematized. These are situations where the dominant constraint is a sanctified spirit of initiative of the decision-maker.

Lastly, situations where none of these constraints appears to clearly dominate the other two are situations where the four approaches can be implemented.

Identifying the dominant constraint might be tricky in practice, at least in some situations. However, referring to Ormerod's [39] general description of an OR consulting project in three phases ( 1 - writing a proposal; 2 - 
designing and planning the intervention; 3 - operating the plan), most of the time enough information will be given by $\mathrm{C}$ at phase 1 for $\mathrm{A}$ to identify if the process is to be implemented in a context where the roles and statuses of most actors are tightly constraining, or where external experts are entrusted to supervise the DA process, or where C's initiative is put on a pedestal. If A misunderstands the context during phase 1, it is likely that her/his bid will be rejected, and if it is not, the numerous in-depth interactions between $\mathrm{A}$ and $\mathrm{C}$ characterizing phase 2 will likely be sufficient to help A to revise her/his interpretation of the situation before launching phase 3 .

Once this analysis of the putative dominant constraint has been done, it is useful to complement it with an analysis of the "problem context" along the lines spelled out by Jackson and Keys [23]. The latter first contrast "systemic" problem contexts, where the systems studied "pose difficult problems because they are often only partly observable, probabilistic, open, have purposeful parts and are subject to behavioral influences" ([23], p.476) with "mechanical" ones, which "are likely to pose easy problems" because they are not plagued by the above difficulties. They then contrast "unitary" with "pluralist" problem contexts, depending on whether the decision-maker is an individual or a collective.

In each of the resulting four kinds of "problem contexts", the dominant constraint can be an irrevocable governance, an unquestionable decisionaiding architecture, or a sanctified spirit of initiative of the decision-maker. A conformist, objectivist or adjustive DA approach can therefore be in order in any of these kinds of "problem contexts." By contrast, when none of the above constraint is dominant, A has more liberty to propose a DA approach, and in such a case Jackson and Keys' typology of problem contexts [23] becomes particularly relevant, in the following sense. Following these authors, because "classical OR" techniques are particularly adapted to mechanicalunitary problem contexts, one can surmise that, in such contexts, an objectivist DA approach is the most adapted; by contrast, systemic-pluralist problem contexts are typically contexts where refraining from thematizing a specific aspect can lead to important errors, which indicates that a reflexive DA approach is commendable. Depending on whether the collective in- 
volved in mechanical-pluralist context problems is a collective of actors with which $\mathrm{C}$ interacts or a collective $\mathrm{C}$, a conformist DA approach or a reflexive one is commendable, respectively. Depending on whether $\mathrm{C}$ is more or less aware of the complexity of the systems at issue, in systemic-unitary context problems, an adjustive DA approach or a reflexive one is commendable, respectively.

The choice of a DA approach is, undoubtedly, a difficult task that cannot be entirely formalized and involves a good deal of common sense and intuition, but one can see that, by investigating the constraints binding the DA process and the nature of the problem context at issue, A should be able in most cases to form a qualified idea of the most relevant DA approach in a given decision situation in phase 1 , or at least in phase 2 , of a typical OR project. Let us now examine what this identification will be useful for.

\subsubsection{Practical implications in terms of validity and legitimacy}

The choice of an approach obviously has numerous implications on how A will work and interact with C. For example, when elaborating models from which recommendations will be derived, depending on the approach chosen, the main task for A will be, respectively, to elaborate implications of postulated exogenous standards (objectivist approach), to gather and analyze empirical observations (conformist), to strive to unveil C's system of values without much interference (adjustive), to search for a mutual understanding with $\mathrm{C}$ (reflexive).

However, from our point of view in this article, the main concrete implication of the choice of approach is that it will shape how DA practitioners will be able to address challenges to the validity and legitimacy of their analyzes and recommendations. Because validity and legitimacy are controversial notions, we do not take a rigid stance on their precise definition. We simply admit that both refer to justifiability (echoing Ormerod's [35] emphasis on the concept of justification in OR science and practice), but that, whereas validity is more concerned with scientific justifiability, legitimacy is more a matter of public justifiability (see [30] for an elaboration of this approach to legitimacy in an applied DA context). 
Objectivist DA approaches assume that, because the formulations and solutions adopted are unquestionable, they must be publicly accepted, which implies that the process is legitimate. Validity is similarly entrenched in the fact that the formulations and solutions are considered unquestionable. If asked to entrench the justification of her/his approach, an analyst implementing an objectivist approach will hence fall back upon the standards and their supposed unquestionability.

In conformist approaches, legitimacy is based on the fact that $\mathrm{C}$ and the people that interact with her/him or observe her/him will consider that her/his decisions correspond to what ought to be done: the acceptability of the decision by $\mathrm{C}$ and the people with whom s/he works determines whether the process is justified or legitimate. Validity is judged by how well the process reflects the best practice in light of existing knowledge that describes the situation and the actors involved.

In adjustive approaches, the legitimacy of the DA process is based on the aspiration to match C's values and preferences as well as possible: outcomes will be considered justified or legitimate if and only if they appear to have captured the idiosyncrasies of $\mathrm{C}$, so that the latter can see them as a truthful expression of hers/his. Validity is then judged by A's competence in diagnosing the situation and eliciting C's values.

As opposed to the other three approaches, reflexive approaches allow the tackling of the legitimacy and validity requirements in more elaborate ways - but, as a consequence, they also can involve more difficult and timeconsuming analyses. This is because reflexive approaches are anchored in the communicative notion of rationality, which is itself based on the idea that there is no "fixed point" on which A and C can fall back upon: every aspect of what can determine a decision can be thematized. Accordingly, in a reflexive approach, any aspect of A's analysis or recommendation can be questioned and, as it is an application of the communicative notion of rationality, A cannot claim that her/his approach is rational unless s/he can provide arguments that are acceptable, not only by $\mathrm{C}$, but also by the scientific community (validity) or by the public (legitimacy). This can create difficult challenges, whose analysis falls beyond the scope of the present 
article (for a partial exploration of these difficulties, see [7]).

\section{Rationality and the object of typologies in the DA literature}

\subsection{Classical typologies in the DA literature and their ambiguities}

The reader will probably identify some familiarities between the typology introduced in the former section and classical typologies found in the DA literature. Among these typologies, possibly the most famous one is based on the descriptive vs. normative dichotomy. Descriptive contributions are concerned with the way people make decisions, as a matter of empirical fact, whereas normative contributions investigate what makes a decision a good one. This distinction has been enriched by Bell, Raiffa and Tversky [4], who added a "prescriptive" term to the dichotomy, designed to capture the contributions of "the methodologists, the consultants (...) concerned with the bottom line: how do you improve the quality of decisions in practice?" ([4], p.ix).

Another classical distinction was proposed by Roy and Bouyssou [48], who distinguished three paths to give meaning to the knowledge produced in DA: the path of realism (quest for descriptions for discovering), the axiomatic path (quest of norms for prescribing) and the constructivist path (quest for working hypotheses for recommending), where the axiomatic path can be combined with any of the other two paths (realism and constructivism).

Having in mind these classical typologies, the reader might see similarities between, on the one hand, the concepts of objectivist, conformist and adjustive approaches as we define them, and, on the other hand, the concepts of normative, descriptive and prescriptive contributions. Similarly, it is tempting to identify what we call a reflexive approach with Roy's notion of constructive path. Tsoukiàs' [56] typology of normative, descriptive, prescriptive and constructive approaches also can be seen as very close to our own typology.

Drawing such parallels would be hasty, however, for several reasons:

First, one might question the philosophical robustness of the abovementioned classical typologies. Indeed, as Bell, Raiffa and Tversky them- 
selves emphasize ([4], p.2), the very structure of their trichotomy can be questioned, because the prescriptive category can be seen as a subcategory of normative. They accordingly see the trichotomy as a convenient tool to classify contributions to decision science on a provisional basis, for exploratory purposes. But they do not give it a more fundamental meaning, and do not see it as anchored in a rigorous philosophical reasoning. Similarly, despite the fact that the terms "constructive" or "constructivism" are often used in the philosophical literature, Roy and Bouyssou themselves never claimed that their contributions had a philosophical dimension or anchorage. The same goes for Tsoukiàs' typology [56]. By contrast, our typology of DA approaches is based on a typology of conceptions of rationality, which is in turn derived from a generalization of Habermas' philosophical theory. This typology of approaches therefore claims to enlist categories that are neatly and rigorously distinguished and whose definition is theoretically and philosophically entrenched.

Second, one might claim that it is unclear what the above classical typologies are concerned to classify. Roy and Bouyssou [48] talk about the meaning of the knowledge produced, which is intuitively easily understandable and compelling, but arguably rather vague: What exactly is the "meaning" of a piece of knowledge? Is it the interpretation that someone has of this piece of knowledge? Is it permissible that several persons diverge in the meaning they give to a given piece of knowledge? Roy and Bouyssou leave these questions and similar ones largely unanswered because their typology does not claim to have a philosophical dimension. But this implies that this typology can be variously interpreted and applied to different sets of objects, which can create ambiguities. Bell, Raiffa and Tversky's formulations are similarly ambiguous. The subtitle of their famous book [4] talks about "descriptive, normative, and prescriptive interactions". However, it is difficult to understand how an interaction can be descriptive only: in the ordinary sense of the terms "description" and "interaction", if one interacts with something, one induces changes in this thing, and one can then no longer be said to have only "described" it. Unless one introduces technical definitions of the terms "description" and "interaction", differing from their 
ordinary sense (which the authors do not), a "descriptive interaction" is a contradiction in terms. A similar comment applies to Tsoukiàs' usage of the term "descriptive" to talk about DA processes [56]: a DA process is a series of actions that eventually aim at providing advices. In that sense a DA process can never be confined to a description of what is the case (a descriptive task), it unavoidably involves envisioning and striving to materialize what should be the case (a normative task). In line with this logic, Bell, Raiffa and Tversky's own application of their trichotomy appears to correspond mainly to disciplinary differences: statistics, mathematics and economics are "normative", psychology and behavioral sciences are "descriptive" and operations research and management science are "prescriptive". This suggests that the proper objects that their trichotomy is convenient to classify are what we termed "tools" in the introduction above. The authors however do not consistently use their typology in this way, and rather at times use the term "prescriptive" to refer to an attitude that consists in striving to apply theories and models to concrete situations, as opposed to the attitude of researchers concerned to answer more general or theoretical questions.

Though we do not question the cogency, usefulness and relevance of these three classical typologies, we therefore claim that they are ambiguous in important respects. This ambiguity is partly due to questionable choices of vocabulary, and partly to the fact that various typologies use the same terms in different senses. It is also a consequence of the fact that these typologies had no philosophical pretentions. But most importantly, these ambiguities are due to the fact that these typologies did not clarify the precise nature of the objects they could be expected to be able to classify. As a consequence, they are rather indiscriminately used to classify tools, processes, approaches, and even disciplines, which arguably is liable to create more confusion than clarification. By contrast, thanks to its anchorage in our reading of Habermas' philosophy, our typology was elaborated in such a way that it has a clearly defined object: DA approaches (ways to conduct the DA process). 


\subsection{The interpretative link between DA tools and conceptions of rationality}

This contrast between our proposed typology and the more classical ones found in the literature suggests that, at this stage, it is important to clarify if our typology, introduced as it was at the level of approaches, can also be applied at the level of tools.

Numerous decision support tools are available today. They range from optimisation techniques to cognitive approaches, from artificial intelligence tools to multiple criteria decision analysis (MCDA) methods, from extremely sophisticated tools to more "soft", natural language oriented and user friendly ones. Each of these tools has been created with a more or less precise (certainly often unconscious) "philosophical" background (see [16]) and with a more or less precise conception of rationality (implicitly) in mind. This inspiration is sometimes reported as an historical fact by the inventors of the tools. Most of the time, however, the link between a given tool and a conception of rationality only becomes visible ex post and is to a large extent interpretative.

For instance, it is tempting to claim that traditional Operational Research techniques such as linear programming or combinatorial optimisation, as well as expected utility theory and game theory (see the discussion in [33]), reflect the strategic conception of rationality underlying what we term objectivist DA approaches. Similarly, one can interpret several decision heuristics as well as some early artificial intelligence knowledge representation techniques as reflecting the norm-regulated conception of rationality underlying conformist DA approaches: they capture the way by which agents and/or experts make judgements and generalize it. Much cognitive analysis can be associated to such an effort. Similarly, several multiple criteria decision support methods can be seen as anchored in the dramaturgic conception of rationality. Several artificial intelligence tools also make implicitly reference to this model of rationality. Note for instance the common argumentation concerning intransitive preferences in decision analysis and non monotonic reasoning in logic $[14,54]$. Finally, several "soft" OR methods and several MCDA methods at least implicitly refer to a concept of communicative rationality close to the one we used to define reflexive DA ap- 
proaches. Indeed, although he cautiously eschewed philosophical references, Roy's [47] understanding of the notion of "constructivism" is arguably close to the communicative conception of rationality as we defined it above. By clearly focussing on the DA process and the structuring issue, Soft Systems Methodology [10] endorses a very similar approach.

In these various cases, the tools used in DA historically emerged, as a matter of fact, from processes that were (more or less explicitly, and more or less consciously) inspired by various conceptions of rationality. And even when no such historical inspiration is acknowledged by the inventors of tools, it is always possible ex post to argue that, at an interpretative level, this or that tool captures what might be called "the spirit" of a given conception of rationality. But beyond historical contingencies and (always disputable) interpretative claims, there is no positive reason to believe that any DA tools is really anchored in specific conceptions of rationality, in the sense that it would be nondetachable from a specific conception or rationality (an idea that echoes, in the terms of rationality, the conclusions of historical debates in the management science literature, on the possibility of methodological pluralism [22]). The corresponding possibility to use, in all four different approaches, tools that might seem to be associated in any one of these approaches, is illustrated in Annex 1.

\subsection{The proper place of rationality}

Based on the elements explored so far, we are now in a position to answer questions Q1-3, from which we started in the introduction:

- Q1: Should one consider that rationality characterizes tools or artifacts or processes or approaches or all of them? A DA process has a rationality: it is the rationality embodied in the DA approach used in this DA process. By contrast, there is no such thing as the rationality of a tool. However, once a tool has been assigned a role in the DA process, this usage of the tool is a part of the DA process and, as such, has a rationality.

- Q2: What does a "rationality" requirement amount to when applied to the above entities? A rationality requirement applied to a given DA pro- 
cess imposes that the Analyst involved should be able to display the DA approach that he used, and explain why it was relevant.

- Q3: Are there various conceptions of rationality, and in that case is it possible to establish a correspondence between specific types of DA tools, processes or approaches and specific conceptions of rationality? There are different types of rationality, embodied in the different types DA approaches that we introduced.

\section{Conclusion}

In this article, we have argued that conceptualizing the notion of rationality can prove very useful to understand DA practices. We took advantage of important insights of Habermas' to establish a typology of conceptions of rationality, and we used this typology to introduce a typology of $D A$ approaches, distinguishing objectivist, conformist, adjustive, and reflexive approaches.

Our reasoning has direct operational implications, which makes it of distinctive interest, not only for philosophers and OR theoreticians, but also for practitioners. We explain how practitioners should reason in practice to identify which DA approach they should implement in a given situation, and then explain how they can take advantage of our analysis to entrench the legitimacy and validity of their recommendations.

However, as repeatedly emphasized, the notions of legitimacy and validity are controversial and their meaning is certainly largely context-dependant and unstable. Accordingly, we do not claim that our reasoning here provides a sufficient picture to elaborate a full-blown theory of validity and legitimacy. Our more reasonable ambition is to have produce a serious account of a factor that plays a key role in determining validity and legitimacy: rationality.

\section{References}

[1] P. Anand, P. K. Pattanaik, and C. Puppe, editors. The handbook of rational and social choice: an overview of new foundations and applications. Oxford University Press, Oxford ; New York, 2009. 
[2] C.A. Bana e Costa, L. Ensslin, E.C. Corrêa, and J.-C. Vansnick. Decision Support Systems in action: Integrated application in a multicriteria decision aid process. European Journal of Operational Research, 113(2):315-335, 1999.

[3] B. Bartkowski. Economic Valuation of Biodiversity: An Interdisciplinary Conceptual Perspective. Routledge, New York, 2017.

[4] D. Bell, H. Raiffa, and A. Tversky. Decision Making : descriptive, normative, and prescriptive interactions. Cambridge University Press, Cambridge, Mass, 1988.

[5] V. Belton and T. Stewart. Multiple Criteria Decision Analysis - An Integrated Approach. Kluwer Academic, Dordrecht, 2002.

[6] D. Bouyssou, T. Marchant, M. Pirlot, P. Perny, P. Vincke, and A. Tsoukiàs. Evaluation and Decision Models - A Critical Perspective. Kluwer Academic, Dordrecht, 2000.

[7] O. Cailloux and Y. Meinard. A formal framework for deliberated judgment, 2018.

[8] H. Calendot and M. Martin. Schéma départemental des espaces naturels sensibles de la Charente-maritime, 2016. Technical report.

[9] A. Charnes, W.W. Cooper, A.Y. Lewin, and L.M. Seiford. Data Envelopment Analysis: Theory, Methodology, and Applications. Springer, 1994.

[10] P. Checkland. Systems Thinking, Systems Practice. Wiley, New York, 1981.

[11] A. David. Models implementation: A state of the art. European Journal of Operational Research, 134(3):459-480, 2001.

[12] L. Dias and A. Tsoukiàs. On the constructive and other approaches in decision aiding. In C.H. Antunes, J. Figueira, and J.N. Climaco, 
editors, Proceedings of the 56th meeting of the EURO MCDA working group, pages 13-28, 2004.

[13] L. C. Dias and J. N. Climaco. Additive Aggregation with Variable Interdependent Parameters: The VIP Analysis Software. The Journal of the Operational Research Society, 51(9):1070-1082, 2000.

[14] J. Doyle and M.P. Wellman. Impediments to universal preference-based default theories. Artificial Intelligence, 49:97-128, 1991.

[15] R.L. Flood and M.C. Jackson. Total systems intervention: A practical face to critical systems thinking. Systems practice, 4(3):197-213, 1991.

[16] J.-L. Genard and M. Pirlot. Multi-Criteria Decision-Aid in a Philosophical Perspective. In D. Bouyssou, E. Jacquet-Lagrèze, P. Perny, R. Slowinski, D. Vanderpooten, and P. Vincke, editors, Aiding Decisions with Multiple Criteria, number 44 in International Series in Operations Research \& Management Science, pages 89-117. Springer US, New York, 2002.

[17] S. Greco, B. Matarazzo, and R. Slowinski. Rough sets theory for multicriteria decision analysis. European Journal of Operational Research, 129(1):1-47, 2001.

[18] J. Habermas. Theorie des kommunikativen Handelns. Suhrkamp, Frankfurt am Main, 1981.

[19] J. Habermas. Faktizitaet und Geltung: Beitraege zur Diskurstheorie des Rechts und des demokratischen Rechtsstaats. Suhrkamp, Frankfurt am Main, 1992.

[20] P. Humphreys, O. Svenson, and A. Vári. Analysing and Aiding Decision Processes. Elsevier, Amsterdam, 2000.

[21] M.C. Jackson. The origins and nature of critical systems thinking. Systems practice, 4(2):131-149, 1991. 
[22] M.C. Jackson. Towards coherent pluralism in management science. Journal of the Operational Research Society, 50(1):12-22, 1999.

[23] M.C. Jackson and P. Keys. Towards a System of Systems Methodologies. Journal of the Operational Research Society, 35(6):473-486, 1984.

[24] D. Kahneman, P. Slovic, and A. Tverski. Judgment under Uncertainty. Cambridge University Press, Cambridge, Mass, 1981.

[25] M. Landry, C. Banville, and M. Oral. Model legitimisation in operational research. European Journal of Operational Research, 92(3):443$457,1996$.

[26] M. Landry, J.L. Malouin, and M. Oral. Model validation in operations research. European Journal of Operational Research, 14:207-220, 1983.

[27] O. I. Larichev and H. M. Moskovich. Unstructured Problems and Development of Prescriptive Decision Making Methods. In P.M. Pardalos, Y. Siskos, and C. Zopounidis, editors, Advances in Multicriteria Analysis, number 5 in Nonconvex Optimization and Its Applications. Springer US, 1995.

[28] R. Layard and S. Glaiser, editors. Cost-Benefit Analysis. Cambridge University Press, Cambridge, Mass, 1994.

[29] M. Martin, Y. Meinard, S. Coq, C. Dehais, and M. Lelièvre. Plan de gestion de l'espace naturel sensible de la tourbière de Landemarais à Parigné. Etude préalable de la végétation, 2017. Technical report.

[30] Y. Meinard. What is a legitimate conservation policy? Biological Conservation, 213(Part A):115-123, 2017.

[31] Y. Meinard, H. Calendot, and M. Martin. Evaluation et redéfinition de la politique départementale en faveur des milieux aquatiques (PADMA). Département de la Gironde, 2015. Technical Report. 
[32] Y. Meinard, C. Dehais, and M. Lelièvre. Document d'Objectifs (DOCOB) de la Zone de Protection Spéciale (ZPS) FR4213813 \Ried de Colmar Sélestat, Haut-Rhin, 2016. Technical report.

[33] J. Moscarola. Organizational Decision Process and ORASA Intervention. In R. Tomlinson and I. Kiss, editors, Rethinking the process of operational research and systems analysis, pages 169-186. Pergamon Press, Oxford, 1984.

[34] R.J. Ormerod. The history and ideas of pragmatism. Journal of the Operational Research Society, 57(8):892-909, 2006.

[35] R.J. Ormerod. Justifying the methods of OR. The Journal of the Operational Research Society, 61(12):1694-1708, 2010.

[36] R.J. Ormerod. OR as rational choice: a decision and game theory perspective. The Journal of the Operational Research Society, 61(12):1761$1776,2010$.

[37] R.J. Ormerod. Logic and rationality in OR interventions: an examination in the light of the critical rationalist approach. Journal of the Operational Research Society, 64(4):469-487, 2013.

[38] R.J. Ormerod. On operationalizing critical pragmatism for professional practice: an open letter to Werner Ulrich. In Ulrich's Bimonthly, MayJune 2016 (Reflections on Critical Pragmatism, Part 8.), 2016.

[39] R.J. Ormerod. The logic and methods of OR consulting practice: towards a foundational view. Journal of the Operational Research Society, $0(0): 1-22,2017$.

[40] E. Paschetta and A. Tsoukiàs. A real-world MCDA application: evaluating software. Journal of Multi-Criteria Decision Analysis, 9(5):205226,2000 .

[41] C.S. Peirce. How to make our ideas clear. In M.P. Lynch, editor, The Nature of Truth: Classic and Contemporary Perspectives, pages 193210. MIT Press, 2001. 
[42] L.D. Phillips. Requisite Decision Modelling: A Case Study. Journal of the Operational Research Society, 33(4):303-311, 1982.

[43] L.D. Phillips and C.A. Bana e Costa. Transparent prioritisation, budgeting and resource allocation with multi-criteria decision analysis and decision conferencing. Annals of Operations Research, 154(1):51-68, 2007.

[44] E.C. Poulton. Behavioral Decision Theory: A new approach. Cambridge University Press, Cambridge, Mass, 1994.

[45] H. Raiffa. Preferences for multi-attributed alternatives. Journal of Multi-Criteria Decision Analysis, 14(4-6):115-157, 2006.

[46] J. Rosenhead and J. Mingers, editors. Rational Analysis for a Problematic World Revisited: Problem Structuring Methods for Complexity, Uncertainty and Conflict. Wiley, New York, 2nd edition, 2001.

[47] B. Roy. Multicriteria Methodology for Decision Aiding. Kluwer Academic, Dordrecht, 1996.

[48] B. Roy and D. Bouyssou. Aide multicritère la décision: méthodes et cas. Economica, Paris, 1993.

[49] H.A. Simon. A Behavioral Model of Rational Choice. The Quarterly Journal of Economics, 69:99-118, 1955.

[50] H.A. Simon. Rational Decision Making in Business Organizations. The American Economic Review, 69(4):493-513, 1979.

[51] H.A. Simon. Administrative Behavior, 4th Edition. Simon and Schuster, New York, 2013.

[52] I. Stamelos and A. Tsoukiàs. Software evaluation problem situations. European Journal of Operational Research, 145(2):273-286, 2003.

[53] T. Tannsjo. Hedonistic utilitarianism. Edinburgh University Press,, Edinburgh, 1998. 
[54] A. Tsoukiàs. Preference modelling as a reasoning process: a new way to face uncertainty in multiple criteria decision support systems. European Journal of Operational Research, 55:309-318, 1991.

[55] A. Tsoukiàs. On the concept of decision aiding process: an operational perspective. Annals of Operations Research, 154(1):3-27, 2007.

[56] A. Tsoukiàs. From decision theory to decision aiding methodology. European Journal of Operational Research, 187(1):138-161, 2008.

[57] W. Ulrich. Critical heuristics of social systems design. European Journal of Operational Research, 31(3):276-283, 1987.

[58] W. Ulrich. Philosophy for professionals: towards critical pragmatism. Journal of the Operational Research Society, 58(8):1109-1113, 2007.

[59] D. Vanderpooten. Modelling in decision aiding. In D. Bouyssou, E. Jacquet-Lagrèze, P. Perny, R. Slowinsli, D. Vanderpooten, and P. Vincke, editors, Aiding Decisions with Multiple Criteria: Essays in Honour of Bernard Roy, pages 195-210. Kluwer Academic, Dordrecht, 2002.

[60] M. Weber. Wirtschaft und Gesellschaft. Mohr, Tubingen, 1922.

\section{Acknowledgements}

We thank B. Roy for very powerful comments and suggestions, and J.-S. Gharbi for important suggestions. Some of the ideas developed in this article originated in a discussion, published in [12], that occurred during the second Young MCDA Researchers Meeting held in Coimbra on October 3rd, 2002, associated to the 56th Meeting of the EURO Working Group on MCDA. The explanatory example used in section 3 was suggested by D. Bouyssou. However, the authors remain solely responsible for this essay. 


\section{Annex 1: Examples of how the same tools can be used under different approaches}

In this annex, we illustrate how the same DA tools might be used in DA processes according to different approaches, as characterized in Section 3. For this illustration, we chose four DA tools that can be interpreted as being associated with different conceptions of rationality:

- Cost-Benefit Analysis [28] (CBA), whose philosophical background might seem to anchor it in the strategic conception of rationality.

- Data Envelopment Analysis [9] (DEA), which measures efficiency in terms of a non-parametrical empirical-based efficiency frontier, given theoretical or practical obstacles to the definition of an economic production function, and might therefore seem to be anchored in the norm-regulated conception of rationality.

- Multi-criteria prioritization through Decision Conferencing $[42,43]$ (DC), which echoes the dramaturgic conception of rationality by assigning to the Analyst the role of a "facilitator", while the Client and/or its representatives are expected to contribute all the "content" of the decision process.

- Soft Systems Methodology (SSM) [10], which might seem inherently linked to the communicative conception of rationality.

Let us now illustrate how each of these DA tools can be used in any of the four DA approaches characterized in Section 3.

\section{1. $C B A$}

An objectivist DA approach. Suppose C asks the help of the Analyst to conduct a CBA, since this tool is required by law. The Analyst takes the criteria couched in law and technical guidelines (e.g. an internal manual) as given and not questionable. The process is justified as legitimate by the assumed validity of the criteria and the technically quality of the analysis.

A conformist DA approach. Suppose C asks the help of the Analyst to conduct CBA, since it is commonly used for similar situations in many 
countries. A applies CBA taking into account her/his knowledge about how the method has been used before, namely avoiding known pitfalls and emulating successful cases. The process is justified as legitimate to the degree that this situation was indeed similar to the cases considered as such, and to the degree that best practices were followed.

An adjustive DA approach. Suppose C asks the help of the Analyst to evaluate options, since this Analyst is an expert in this type of problems. A assesses that CBA is an appropriate method to reflect C's values in this situation. A applies CBA and incorporates in her/his modeling the judgment of $\mathrm{C}$, e.g. in deciding how to discount future values. The process is justified as legitimate to the degree that A was competent in her/his work to reflect C's judgment and needs.

A reflexive DA approach. Suppose C asks the Analyst help to evaluate options, since this Analyst is a DA expert with good process conduction skills. A proposes the use of CBA at a given point of the decision process, just to check if under this perspective there would be a clear winner. Many arbitrary options involved in the modeling exercise are discussed with A, not neglecting theory and customary practice of CBA. Alternative models are developed as tools to foster discussion. The process is justified as legitimate to the degree that $\mathrm{A}$ and $\mathrm{C}$ deem that the results correspond to coherent arguments that reflect the issues that were settled during the discussions.

\section{2. $D E A$}

An objectivist DA approach. Suppose A asks the Analyst help to conduct DEA to evaluate hospitals, following a "Ministry of Health Performance Evaluation Green Book". This manual indicates BCC as the DEA model to be used and enlists the names of inputs and outputs that should be included. A tries to follow the manual as closely as s/he can, with some freedom to define options that the manual does not cover, e.g., how to measure each input or output. The process is justified as legitimate to the degree that the manual was followed and the analysis was technically well performed, that is: the degree to which the exogeneously given standards were adhered to. 
An conformist DA approach. Suppose C asks the Analyst help to conduct DEA to evaluate hospitals, since it is commonly used in many similar situations. A applies DEA taking into account her/his knowledge about how the method has been used before, namely avoiding known pitfalls and using inputs and outputs that are common in past highly-regarded studies. Past studies evaluating the productivity of hospitals lead her/him to reject an assumption of constant returns to scale, and hence to use a $\mathrm{BCC}$ model. The process is justified as legitimate to the degree that best practices were followed.

An adjustive DA approach. Suppose $\mathrm{C}$ asks an Analyst help to evaluate hospitals, since this Analyst is an expert in this type of problems. A deems DEA is the most appropriate tool for this task, according to her/his expertise. S/he interviews A to find out constraints and preferences on how to conduct the analysis, e.g., to know which factors are deemed more important, or which factors are most problematic in terms of data gathering. The process is justified as legitimate to the degree that A was competent in her/his work to reflect A's judgment and needs.

A reflexive DA approach. Suppose $\mathrm{C}$ asks an Analyst help to evaluate hospitals. The problem is initially cast as an MCDA evaluation, but the difficulties encountered lead $\mathrm{A}$ and $\mathrm{C}$ to agree that a change of perspective is necessary. Eventually this leads to the conclusion that DEA seems more adequate to C's conception of hospital evaluation as an efficiency evaluation. A returns to scale assumption is discussed, as well as the choice of inputs and outputs. The discussion is enriched by building several prototypical models following different options, allowing exploring and learning the consequences of the different modeling options. The process is justified as legitimate to the degree that $\mathrm{A}$ and $\mathrm{C}$ deem that the results correspond to coherent arguments that reflect the issues that were settled during the discussions.

\subsection{Multi-criteria prioritization through DC}

An objectivist DA approach. Imagine that $\mathrm{C}$ wants to elaborate an action plan on environmental sites in her/his vicinity, including a spatial prioritization of known natural sites, based on known information about 
them, including naturalistic data, information concerning flooding risk, feasibility and cost of various possible actions on the different sites, and so on. $\mathrm{C}$ wants to take advantage of the insights that renown local experts can provide, because they have a precise knowledge of all the sites concerned. The knowledge of these experts is taken as an absolute reference. Unfortunately, although the experts are able to make informed claims on particular aspects, they all have limited competences, and their views therefore have to be aggregated to identify an overall prioritization. Multi-criteria prioritization through DC is used to identify the collective view of this group of experts.

An conformist DA approach. $\mathrm{C}$ is willing to elaborate an action plan on environmental sites in her/his vicinity, but most of the natural sites $\mathrm{s} /$ he is about to prioritize as part of this action plan are privately owned, and a large series of economic activities are based on these sites. $\mathrm{C}$ wants to identify sites where s/he can act. A proposes to use Multicriteria prioritization through DC so has to identify where C's actions can be acceptable by land owners, based on DC workshops with representatives of land owners or representatives of the corresponding various economic sectors.

An adjustive DA approach. $\mathrm{C}$ is concerned to prioritize natural sites in her/his vicinity as part of an action plan to be elaborated. She and her main collaborators can state features of natural sites that they value, but are unable to say in the abstract which values are more or less important in their eyes, which makes it impossible for them to define a global strategy to prioritize all the sites concerned. A proposes to use Multi-criteria prioritization through DC including her main collaborators to clarify the value underlying their choices and judgments and systematize them.

A reflexive DA approach. A initially wants to use the information available on natural sites in her/his vicinity, to prioritize sites for restoration purposes. S/he asks for A to help her compute the expected benefits of various portfolios of actions on various sites, using Multi-criteria prioritization through DC involving a handful of her key collaborators. When unfolding the usual steps of the method, A becomes aware that the very ambition 
to prioritize sites for restoration purposes might be ill-conceived, because $\mathrm{C}$ fails to identify that numerous stakeholders, which are not involved in the DC, find restoration actions illegitimate, for reasons that $\mathrm{C}$ has never investigated. A therefore suggests that the whole decision process should be reshuffled, and that a new DC process should launched, involving representatives of stakeholders, so as to identify a new overall environmental strategy acceptable to all.

\section{4. $S S M$}

An objectivist DA approach. Suppose SSM is the chosen method, since the company's president firmly contends that this is the methodology that should be used, given its coherence and theoretical appeal, which he admires since he learnt the method at university. The Analyst was hired in the sequence of a job offer suggested by the president where knowledge of SSM was specifically required. The process is legitimated internally by the support of the president to making SSM the norm for these meetings. A's role is to abide by the standard according to the president's requests.

An conformist DA approach. Suppose SSM is the chosen method for its track record of successful past interventions, by many facilitators in many organizations. A has studied extensively these past applications and uses this knowledge to emulate the best practitioners. The process is legitimated internally by the ample evidence presented by $\mathrm{A}$ in support of method's ability to succeed in allowing groups to move forward in problematic situations.

An adjustive DA approach. Suppose the Analyst is highly regarded for his mastery of OR tools. When the president approached him for advice on how to improve strategic decision-making in the company, A indicated SSM as the most appropriate tool due to the possibilities if offers to lead the various persons involved to express their values and preferences, thanks to soft communication facilitating tricks. The process is legitimated internally by A's reputation and her/his perceived ability to facilitate the discussions.

A reflexive DA approach. Suppose that the Analyst is often invited to serve as an OR analyst at staff meetings. In this meeting, given the 
group's purpose, he proposed the use of SSM as an exploratory analysis. Later, s/he argued that the analysis might call for the use of other OR models, or it might even happen that the SSM analysis would be considered sufficient to support some decisions without further analysis. The group agreed, knowing also that if the SSM analysis happened to become unproductive, then the Analyst would be the first one to propose the use of an alternative approach. The process is legitimated internally by the group's agreement.

Theses examples illustrate that the philosophical background that can be interpreted as underlying a given tool does not simply percolates to the process in which the tool is used. Although the construction of some tools might have been associated, as a matter of historical fact, with a given conception of rationality, and although one can always speculate on the interpretative link between a given tool and a given conception of rationality, once the tools are embedded in a DA process, they can become independent from conceptions of rationality with which they are historically or interpretativelly associated. 